\title{
LETTER
}

\section{ORI monitoring allows a reduction of time with hyperoxia in critically ill patients: the randomized control ORI ${ }^{2}$ study}

\author{
Sigismond Lasocki ${ }^{*}$, Antoine Brochant, Maxime Leger, Thomas Gaillard, Pierre Lemarié, Soizic Gergaud \\ and Pauline Dupré
}

(c) 2019 The Author(s)

Dear Editor,

After decades of fear of hypoxia, it is now widely accepted that hyperoxia is deleterious too [1, 2]. This is the rationale for recent recommendations to target peripheral oxygen saturation $(\mathrm{SpO} 2) \leq 96 \%$ [3]. However, $\mathrm{SpO} 2$ monitoring may not be sufficient since elevated partial arterial oxygen pressure $(\mathrm{PaO} 2)$ is not recognized once $\mathrm{SpO} 2 \geq 98 \%$, indeed, critically ill patients may spend as much as $60 \%$ of the time with hyperoxia [4]. The oxygen reserve index (ORI), measured non-invasively by a pulse-oximeter, correlates to elevated $\mathrm{PaO}_{2}$ (for $\mathrm{PaO} 2>80-100 \mathrm{mmHg}$ [5]). We hypothesized that using ORI to set oxygen in critically ill patients would reduce the time with moderate hyperoxia $\left(\mathrm{PaO}_{2} \geq 100 \mathrm{mmHg}\right)$ compared to monitoring $\mathrm{SpO} 2$ (with upper limits) alone.

We randomized 150 adult patients, mechanically ventilated for a predictable duration $\geq 2$ days to either ORI or control group (ClinicalTrial: NCT02878460; see esm). All the patients were monitored using Rainbow ${ }^{\circledR}$ pulse-oximeter sensors connected to ROOT monitors (MASIMO, USA). Nurses were instructed to decrease $\mathrm{O} 2$ rate when ORI was $\geq 0.01$ (ORI group) or when $\mathrm{SpO} 2$ was $\geq$ prescribed upper limit (control group) (Supplementary Fig. 1e). Seventy-five patients were analyzed in the ORI group and 71 in the control group (Supplementary Fig. 2e). Patients in both groups were similar, except for the presence of shock at ICU admission (48 (64\%) vs 32 (45\%) in ORI and control groups, $p=0.022$; Table 1e). Patients were most often admitted for urgent surgery and

*Correspondence: sigismond@lasocki.com

Département Anesthésie-Réanimation, UBL Université d'Angers, CHU

Angers, 4 rue Larrey, 49933 Angers Cedex 9, France had frequent lung damage. The median duration of follow-up was similar (6 (2-13) vs $5(2-16)$ days, $p=0.71)$. We analyzed 2455 arterial blood gasses, 1545 days and $36.929 \mathrm{~h}$ of oxygen therapy (medians 166 (56-306) vs 111 (40-396) $\mathrm{h} /$ patient for ORI and control groups, $p=0.58)$. ORI monitoring allowed a significant reduction in the percentage of days with hyperoxia (14 (0-33) vs $33(11-56) \%$ for ORI vs control, $p=0.003)$ without an increase in the percentage of days with hypoxia (Supplementary Fig. 3e). The percentage of time (in hours) spent with $\mathrm{PaO} 2 \geq 100$ or $\geq 120 \mathrm{mmHg}$ was also much lower using ORI (Table 1). We observed no statistically significant differences in mean daily $\mathrm{PaO}_{2}$ or $\mathrm{FiO}_{2}$, but the time spent with a $\mathrm{FiO} 2$ of 0.21 was greater in the ORI group (Table 1). There was no difference in any other clinical outcome.

The use of ORI monitoring to titrate oxygen rates allowed an important reduction of the time spent with hyperoxia compared with the use of $\mathrm{SpO} 2$ alone, probably because nurses are reluctant to decrease oxygen rates when $\mathrm{SpO} 2$ is in a normal range. A nurse-driven protocol to adjust $\mathrm{FiO} 2$ according to $\mathrm{SpO} 2$ was already in place in our unit, explaining why the percentage of time with hyperoxia we observed in the control group was much less than usually reported (30 vs 60\%) [4]. This strategy to decrease oxygen rate according to ORI (which detects high $\mathrm{PaO} 2$ ) may thus be even more efficient in units where there is no protocol to adjust oxygen rates. $\mathrm{SpO} 2$ could remain a warning for hypoxia and ORI for hyperoxia. Larger studies are needed to evaluate the clinical benefit of this strategy. 
Table 1 Main outcomes

\begin{tabular}{|c|c|c|c|}
\hline & ORI $(n=75)$ & Control $(n=71)$ & $p$ \\
\hline \multicolumn{4}{|l|}{ Primary outcomes } \\
\hline Percentage of days with hyperoxia, $\%$ & $14(0-29)$ & $28(9-50)$ & $0.003^{*}$ \\
\hline Number of days with hyperoxia & $1(0-2)$ & $2(1-3)$ & 0.023 \\
\hline \multicolumn{4}{|l|}{ Secondary outcomes } \\
\hline Percentage of days with hypoxia, \% & $12(0-31)$ & $5(0-20)$ & 0.31 \\
\hline Number of days with hypoxia & $1(0-3)$ & $1(0-2)$ & 0.24 \\
\hline Number of days under oxygen therapy & $7(3-13)$ & $5(2-17)$ & 0.78 \\
\hline ABG (number during follow-up) & $14(5-25)$ & $10(5-25)$ & 0.82 \\
\hline Duration of oxygen therapy (hours) & 166(56-306) & $111(40-396)$ & 0.58 \\
\hline Percentage of time (hours) with $\mathrm{PaO} 2 \geq 100 \mathrm{mmHg}$, \% & $7.4(0-24.8)$ & $17.3(3.8-43.1)$ & 0.0069 \\
\hline Percentage of time (hours) with $\mathrm{PaO} 2 \geq 120 \mathrm{mmHg}$, \% & $0(0-7.2)$ & $5.6(0-18.1)$ & 0.0037 \\
\hline Mean daily $\mathrm{PaO} 2, \mathrm{mmHg}$ & $84 \pm 25$ & $83 \pm 28$ & 0.36 \\
\hline Mean FiO2/patient & $0.32(0.26-0.43)$ & $0.36(0.30-0.43)$ & 0.07 \\
\hline Hours of $\mathrm{MV}$ under an $\mathrm{FiO} 2=0.21$, hours & $0(0-34)$ & $0(0-8)$ & 0.0036 \\
\hline MV duration, days & $6(3-12)$ & $4.5(2-14)$ & 0.45 \\
\hline MV free days at day 28 , days & $19(2-25)$ & $19(0-25)$ & 0.82 \\
\hline At least one atelectasis & $22(29)$ & $18(25)$ & 0.59 \\
\hline VAP & $18(24)$ & $24(34)$ & 0.19 \\
\hline ICU LOS, days & $8(4-17)$ & $8(5-17)$ & 0.68 \\
\hline ICU mortality & $16(21)$ & $17(24)$ & 0.84 \\
\hline
\end{tabular}

Values are median (Q1-Q3), mean $\pm \mathrm{SD}$ or $n(\%)$

$H$ hyperoxia defined as a $\mathrm{PaO} 2 \geq 100 \mathrm{mmHg}, h$ hypoxia defined as a $\mathrm{PaO} 2<60 \mathrm{mmHg}, A B G$ arterial blood gases, FiO2 fraction of inspired oxygen, $\mathrm{PaO} 2$ arterial partial pressure of oxygen, $M V$ mechanical ventilation, VAP ventilator-associated pneumonia, ICU intensive care unit, LOS length of stay

${ }^{*} p<0.0294$ considered significant according to Pocock's correction for intermediate analysis (see esm for methods)

\section{Electronic supplementary material}

The online version of this article (https://doi.org/10.1007/s00134-019-05732-9) contains supplementary material, which is available to authorized users.

\section{Acknowledgements}

The CHU d'Angers was the sponsor of the study. MASIMO provided the sensors at no cost, but was not involved in any aspect of the study.

\section{Compliance with ethical standards}

\section{Conflicts of interest}

$\mathrm{SL}$ received speaking fees from MASIMO. All the other authors declare that they have no conflict of interest.

\section{Open Access}

This article is distributed under the terms of the Creative Commons Attribution-NonCommercial 4.0 International License (http://creativecommons.org/ licenses/by-nc/4.0/), which permits any noncommercial use, distribution, and reproduction in any medium, provided you give appropriate credit to the original author(s) and the source, provide a link to the Creative Commons license, and indicate if changes were made.

\section{Publisher's Note}

Springer Nature remains neutral with regard to jurisdictional claims in published maps and institutional affiliations.

\section{Accepted: 5 August 2019}

Published online: 13 August 2019

\section{References}

1. Chu DK, Kim LH, Young PJ, Zamiri N, Almenawer SA, Jaeschke R, Szczeklik W, Schunemann HJ, Neary JD, Alhazzani W (2018) Mortality and morbidity in acutely ill adults treated with liberal versus conservative oxygen therapy (IOTA): a systematic review and meta-analysis. Lancet 391:1693-1705

2. Kilgannon JH, Jones AE, Parrillo JE, Dellinger RP, Milcarek B, Hunter K, Shapiro NI, Trzeciak S, Emergency Medicine Shock Research Network I (2011) Relationship between supranormal oxygen tension and outcome after resuscitation from cardiac arrest. Circulation 123:2717-2722

3. Siemieniuk RAC, Chu DK, Kim LH, Guell-Rous MR, Alhazzani W, Soccal PM, Karanicolas PJ, Farhoumand PD, Siemieniuk JLK, Satia I, Irusen EM, Refaat MM, Mikita JS, Smith M, Cohen DN, Vandvik PO, Agoritsas T, Lytvyn L, Guyatt GH (2018) Oxygen therapy for acutely ill medical patients: a clinical practice guideline. BMJ 363:k4169

4. Suzuki S, Eastwood GM, Peck L, Glassford NJ, Bellomo R (2013) Current oxygen management in mechanically ventilated patients: a prospective observational cohort study. J Crit Care 28:647-654

5. Applegate RL 2nd, Dorotta IL, Wells B, Juma D, Applegate PM (2016) The relationship between oxygen reserve index and arterial partial pressure of oxygen during surgery. Anesth Analg 123:626-633 